\begin{tabular}{|l|l|}
\hline & \\
\hline
\end{tabular}

SEÇÃO: ESTUDOS BAKHTINIANOS CONTEMPORÂNEOS

\title{
As noções bakhtinianas de linguagem e enunciado
}

\author{
The bakhtinian notions of language and utterance \\ Los conceptos bajtinianos de lenguaje e enunciado
}

\author{
Luciane de Paula ${ }^{1}$ \\ orcid.org/0000-0003-1727-0376 \\ lucianedepaula1@gmail.com
}

\section{José Antonio Rodrigues Luciano $^{2}$ \\ orcid.org/0000-0003-1748-8279 \\ j.luciano@unesp.br}

Recebido em: 17/11/2021 Aprovado em: 17/11/2021 Publicado em: 10/02/2022
Resumo: Neste artigo, a proposta é refletir a respeito da relação enunciado e linguagem presente no pensamento filosófico do Círculo de Bakhtin. Os objetivos são: a) compreender como o grupo de filósofos russos elabora e delimita sua concepção de linguagem e enunciado; e b) conceber uma ontologia capaz de refletir acerca da existência humana. O método dialético-dialógico desenvolvido pelo Círculo pauta a discussão. O estudo leva aos resultados de que a construção conceitual de linguagem é realizada dialogicamente, na fronteira das disciplinas sobretudo das Ciências Humanas (mas não apenas) - como música, literatura, linguistica, artes plásticas, biologia, psicologia, sociologia, entre outras. Estas, por sua vez, são unificadas em torno do problema da linguagem, materializada no ato enunciativo, como modo de efetivação do homem, em seu acabamento ético e estético no mundo. A relevância desta reflexão se volta à pertinência da filosofia da linguagem bakhtiniana como aporte para análises de enunciados visuais, vocais/sonoros e/ou sincréticos, além de e com a materialidade verbal, sobre a qual os pensadores do Círculo se centraram de maneira privilegiada.

Palavras-chave: Circulo de Bakhtin. Corpo. Linguagem.

Abstract: In this article, the propose is to reflect about the relation between utternace and language presented in Bakhtin Circle's philosophical thinking. The objectives are: a) to comprehend how the group of Russian philosophers elaborate and delimitate their conception of language and utterance; and b) to conceive an ontology able to reflect about human existence. The method dialect-dialogic developed by the Circle sustain the discussion. The study demonstrates that the results of a conceptual construction of language is realized dialogically, in frontier of subjects, mainly of Human Sciences (but not only) - such as music, literature, linguistic, plastic arts, biology, psychology, sociology, among others. These, in turn, are unified around the problem of language, materialized in the enunciative act, as mode of effectuation of the human, in their ethic and aesthetic finishing in the world. The relevance of this reflection turns to the pertinence of the Bakhtinian philosophy of language as contribution to analysis of visual, vocal/ sound and/or syncretic utterances, besides and with the verbal materiality, on which the Circle's thinkers focused in a privileged way.

Keywords: Bakhtin Circle. Body. Language.

Resumen: En este artículo, la propuesta es reflexionar sobre la relación entre el enunciado y el lenguaje presente en el pensamiento filosófico del Círculo de Bakhtin. Los objetivos son: a) comprender cómo el grupo de filósofos rusos elabora y delimita su concepción del lenguaje y el enunciado; yb) concebir una ontología capaz de reflexionar sobre la existencia humana. El método dialéctico-dialógico desarrollado por el Círculo guía la discusión. El estudio da como resultado que la construcción conceptual del lenguaje se lleva a cabo de manera dialógica, 
en las fronteras de disciplinas, especialmente las Ciencias Humanas (pero no solo) - como la música, la literatura, la lingüistica, las artes plásticas, la biologia, la psicología, la sociología, etc. entre otros. Estos, a su vez, se unifican en torno al problema del lenguaje, materializado en el acto de la enunciación, como forma de hacer efectivo al hombre, en su terminación ética y estética en el mundo. La relevancia de esta reflexión gira en torno a la relevancia de la filosofía del lenguaje bajtiniana como una contribución al análisis de los enunciados visuales, vocales / sonoros y / o sincréticos, además de y con la materialidad verbal, en la que los pensadores del Círculo se enfocaron en un camino privilegiado.

Palabras clave: Círculo de Bajtín. Cuerpo. Languaje.

\section{Introdução}

Ao elaborar e delimitar sua filosofia da linguagem, o grupo de intelectuais russos atuantes na União Soviética no século XX, que ficou conhecido como Círculo de Bakhtin, buscou conceber, a partir da virada linguística na filosofia durante a passagem do século XIX para o XX, uma linguagem que fosse a própria constituição do homem e do mundo, um "mundo dos signos", conforme propõe Volóchinov (2017), no qual o homem efetiva sua existência e todas as coisas, onde ele nasce, vive e morre. Nessa perspectiva, a linguagem perde seu caráter de mera representação (a mimese aristotélica) do mundo, reflexo do real.

Bakhtin, Medviédev, Volóchinov e os demais pensadores do Círculo (como Jakubinskij, Kanaev e Sollertinskij, por exemplo), em seus textos, utilizam terminologias de outras áreas (como, por exemplo, da música, da biologia, entre outras) para se referirem à linguagem. Além disso, é comum encontrarmos termos, por exemplo, como texto, material sígnico, signo, produto de criação ideológica, entre outros, variando entre si - ora como "sinônimos", ora como lexemas que remetem a concepções distintas. Alguns exemplos de confirmação teórica com flutuação terminológica, em autores diferentes, podem ser vistos, rapidamente em: "Todos os produtos da criação ideológica - obras de arte, trabalhos científicos, símbolos e cerimônias religiosas e etc. - são objetos materiais e partes da realidade que circundam o homem" (MEDVIÉDEV, 2012, p. 48), "o texto é realidade imediata (realidade do pensamento e das vivências)" (BAKHTIN, 2011, p. 307) ou, em relação a qualquer signo, posto "que é não apenas um reflexo, uma sombra da realidade, mas também uma parte material dessa mesma realidade" (VOLOCHINOV, 2017, p. 94).

A diversidade de opções de termos torna-se possivel, pois as palavras utilizadas pelo Círculo, em russo, muitas vezes, recobrem um amplo campo semântico, como é o caso dos lexemas Riétch (língua, linguagem, discurso, fala, conversa), slovo (palavra, vocábulo, termo, discurso, verbo), iazik (língua e linguagem), entre outros. Diferentemente do que ocorre no português brasileiro, por exemplo, que utiliza apenas o lexema "discurso"

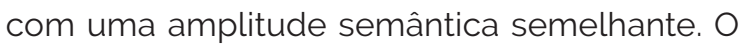
repertório linguístico russo permite aos autores do Círculo poder pensar a linguagem de forma abrangente a partir de uma única materialidade, uma vez que ela está inserida a um conjunto geral de signos ${ }^{3}$ e sua concretização está condicionada às leis desse conjunto. As peculiaridades de cada material sígnico aparecem de acordo com as condições do campo de comunicação discursiva (suas leis e finalidades próprias), nos diversos "tipos de enunciados" (entendidos como gêneros do discurso)

Segundo Bakhtin, "o enunciado se insere no campo da ideologia, mas as formas típicas dos enunciados, isto é, os gêneros, pertencem à linguagem" (2016, p. 134). Todavia, por ser impossivel conceber um sem o outro, posto que o discurso é lingua(gem)4 in actu, o filósofo russo acrescenta que é "inadmissivel contrapor lingua e discurso em qualquer que seja a forma. O discurso é tão social quanto a língua. As formas de enunciados também são sociais e, como a língua, são igualmente determinadas pela comunicação" (2016, p. 117).

Assim, embora o Círculo utilize variação terminológica vasta, é por meio da palavra, sobre-

\footnotetext{
Saussure se referia a esse conjunto geral dos signos como pertencente à semiologia.

Em russo, a palavra vyskazyvanie significa, ao mesmo tempo, enunciação e enunciado - outro exemplo de modo de ver/viver o mundo. A ideia (enunciação) só é possivel semiotizada a partir de alguma materialização (enunciado) e a concretude só é possivel porque concebida como ideia. Assim, enunciação/enunciado não se dissociam, uma vez que constituem a unidade da lingua/linguagem como ato prático social.
} 
tudo da palavra no romance, que os pensadores russos elegem seu objeto central de estudos da linguagem. A escolha da palavra ocorre, conforme expõe Volóchinov (2017), em Marxismo e Filosofia da Linguagem, porque a palavra é compreendida como o meio mais representativo, mais puro dos signos, pela clareza de sua estrutura e pelo fenômeno ideológico que manifesta, bem como possui uma elasticidade (possui uma "neutralidade" que a permite cumprir qualquer função ideológica), o que favorece para melhor explicar as principais formas ideológicas da comunicação discursiva. Os demais signos (visual e sonoro) são especializados em campos particulares de produção ideológica. Além disso, o autor também destaca que os signos visuais e sonoros são envolvidos pelo universo verbal, emergem nele e não podem ser dissociados completamente dele. Acrescentamos: a afirmação contrária também é legítima, a palavra, por mais autônoma que seja, não pode ser isolada dos outros signos não-verbais. Verbal, visual e sonoro estão entrelaçados, de maneira indissociável, constituindo uma única linguagem, como afirma Bakhtin. A essa noção, existente no Círculo, Paula (2017), Paula e Serni (2017) e Paula e Luciano (2020a, 2020b, 2020c, 2020d, 2020e), calcados em Joyce ${ }^{5}$ e na Poesia Concreta, têm utilizado o termo verbivocovisualidade, especialmente para refletirem sobre o sincretismo discursivo.

O estudo da palavra, como conceitua Volóchinov (2013), especificamente no romance, ganha relevância, especialmente em Bakhtin, uma vez que "o objeto fundamental, 'especificador' do gênero romanesco, que cria sua originalidade estilistica, são o falante e sua palavra" (BAKHTIN, 2015b, p. 124). Além disso, as etapas de desen- volvimento histórico do romance, como estuda Bakhtin (2015a, 1987), de maneira concomitante, em Problemas da Poética de Dostoiévski, e em Cultura Popular na Idade Média e no Renascimento: o contexto de François Rabelais, são fontes do uso da palavra em várias instâncias da comunicação discursiva, ou seja, as suas formas, a sua estrutura dialógica e dos gêneros discursivos, nos quais habitam, já que o romance é encarado como simulacro da vida, pois, para Bakhtin,

O romance é uma enciclopédia de gêneros discursivos primários; não um romance, mas o gênero romanesco (cartas, diálogos correntes, diários, análises <?>, protocolos, confissões, relatos dos costumes, etc.). Por isso o romance é o material mais importante para a o estudo desses gêneros primários (embora se deva levar em conta que aqui esses gêneros, retirados das condições da comunicação discursiva real e subordinados aos objetivos do romance, sofreram transformações em diferentes graus) (2016, p. 141)

A palavra não é estudada pelo Círculo apenas do ponto de vista linguístico, mas, pelo que demonstra a citação, ela é entendida de forma alargada, como linguagem materializada em gêneros discursivos por meio de enunciados concretos. Assim como outros termos (como os mencionados), a palavra ganha status de enunciado (lugar de acontecimento concreto da linguagem, pois, fora dele, ela é apenas pare de um sistema abstrato) e se relaciona ao sujeito que a utiliza. Em consonância com a filosofia bakhtiniana, ressaltamos que

Qualquer enunciado concreto é um ato social. Por ser também um conjunto material peculiar - sonoro, pronunciado, visual - o enunciado ao mesmo tempo é uma parte da realidade social. Ele organiza a comunicação que é voltada para uma reação de resposta. Ele mesmo reage a

\footnotetext{
5 O termo verbivocovisualidade foi usado por Joyce para tratar a linguagem romanesca (especialmente a desenvolvida por ele na elaboração de Finnegans Wake, mas, segundo suas reflexões, a concepção pode ser ampliada à linguagem como um todo). O autor elabora a perspectiva de que a constituição verbal contém, em si, o que ele designa como verbivocovisualidade, pois entende a ideia mental causada pela descrição e pela narração romanesca como visual e a constituição acústica, formada pela composição lexical e sintática de sua obra (com mistura de inglês e dialeto irlandês, considerando breves e longas que marcam átonas e tônicas na composição prosódica de embalo da leitura em voz alta etc) como elementos que marcam avocalidade/sonoridade na e da própria língua. Essa concepção vai ao encontro da noção saussureana de signo, composto por significante (matéria acústica - vocal, portanto) e significado (conceito mental - entendido por Joyce como visual). Não nos esquecendo que o Círculo bakhtiniano não abandona a noção de signo, apenas o coloca em movimento ao trazer de volta aos estudos da linguagem o homem e a história, com suas valorações (a ideologia), a concepção de Joyce, de outra maneira, assim como a de Saussure, integram o objeto de estudo do projeto bakhtiniana de filosofia da linguagem. Em uso, o signo ideológico não é encarado isoladamente, mas de maneira integrada, pois constitutivo do homem, com sua voz, seu tom, sua gestualidade, aparência, movimentação, corpo etc. Além disso, a imagem mental vocovisual semiotiza a concretude integral da língua(gem) pelo verbal, que deixa de ser "meramente" verbal, pois, como entende Joyce e, depois, explora, em sua máxima potência, os poetas concretos (especialmente, o grupo Noigandres - mas, não só), ele (o verbal) já é, em si, verbivocovisual.
} 
algo: ele é inseparável do acontecimento da comunicação (MEDVIÉDEV, 2012, p. 183).

O enunciado - como observamos no trecho citado - é o lugar da linguagem, efetivação da sua existência material. No enunciado, o Círculo unifica o problema da linguagem. Consequentemente, o mundo dos signos e o homem, tendo sua existência efetivada apenas como sujeito de linguagem, realizam-se no enunciado concreto.

Desse ponto de vista é que, neste artigo, propomo-nos a investigar a concretização da palavra, tendo em vista seu projeto de dizer interno e externo, potencial e explícito, entendido por nós, hoje, de maneira extemporânea, a partir do Círculo, associada a Joyce e aos poetas concretos, como verbivocovisual. Para isso, discutimos, a seguir, as noções de linguagem e enunciado. Este artigo se caracteriza como metalinguístico, uma vez que utiliza a filosofia bakhtiniana para refletir sobre ela mesma, especificamente sobre as noções de linguagem e enunciado. Dessa forma, os estudos do Círculo russo são, ao mesmo tempo, fundamentação teórica que ampara a discussão realizada por nós e objeto de nosso estudo.

\section{Linguagem e enunciado: potencial e expressão material}

O homem está situado no eixo da arquitetônica do mundo concreto para Bakhtin, devido à sua capacidade de tomada de consciência semiótica e de reflexão sobre os signos. Antes mesmo desse processo em relação ao material semiótico, o homem se faz linguagem, pressupõe o signo, por meio dele interpreta outros signos. A consciência se constitui como um "meta-signo" e se insere (é inserida) no complexo elo da cadeia discursiva organizada socialmente, o que evidencia o caráter dialógico do sujeito. O homem não preexiste ao mundo dos sentidos, não está fora dos signos, tampouco os controla (apenas relativamente).

Se o homem só existe enquanto sujeito de linguagem no enunciado concreto da comunica- ção discursiva, podemos inferir, dessa afirmação, que o corpo se efetiva no enunciado ao mesmo tempo em que o próprio corpo é um enunciado. Para Ponzio (2016), é possível dizer que o próprio corpo humano é o material primário de atribuição de função sígnico-ideológica, de modo que a realidade externa é um material sígnico secundário, que tem o corpo como referência. Por essa concepção, o corpo humano se torna ponto de partida para a expressão avaliativa do homem no mundo, sua corporificação semiótica.

Nesse sentido, a vida se expressa em ato de linguagem, em uma relação dialógica intercorpórea organizada no seio vida social. O diálogo, na filosofia bakhtiniana, consiste na impossibilidade psicobiossemiótica de fechamento, de indiferença e de acabamento do homem e da vida. O sujeito é um ser destinado à incompletude, constantemente em busca de sua integralidade no e com o outro. ${ }^{6}$ Diálogicidade e intercorporeidade estão vinculadas na relação psicobiossemiótica dos indivíduos. Há, assim, uma dialógica da vida (PONZO, 2016).

Em decorrência da sua autoinsuficiência, o sujeito, ao realizar-se e ao realizar (n)o enunciado, assume uma orientação social dialógica. Isso significa que ele, por meio do enunciado - está voltado para o(s) outro(s), constituindo-se no elo da cadeia discursiva e a construção de sentido acontece na relação com outros enunciados-sujeitos, pois "em tudo através do que o homem se exprime exteriormente (e, por conseguinte, para o outro) - do corpo à palavra - ocorre uma tensa interação do eu com o outro" (BAKHTIN, 2011, p. 350).

Em Para Filosofia do Ato Responsável, Bakhtin (2010) afirma ter a vida dois centros de valor: o eu e o outro, imprescindivel e radicalmente diferentes ao passo em que se relacionam. Sob esses dois pontos, o Ser se organiza em momentos efetivos de linguagem.

A contraposição efetiva entre o eu e o outro a partir do ato em um evento único e singular se torna o princípio arquitetônico do mundo concreto. O homem passa a existir enquanto ato de

\footnotetext{
6 Em Freud, por exemplo, a busca por completude aparece inicialmente na relação do bebê com a função materna (não necessariamente, embora frequentemente, seja a mulher) até a castração feita pela função paterna (aqui a mesma afirmação sobre a função materna é válida). Depois da "expulsão do paraiso" (da completude com a função materna), a busca pela totalidade do sujeito acontece no processo de falicização (lugar de fantasia para a construção da completude, seja com objetos, seja pessoas).
} 
linguagem e na relação com o outro, em determinado acontecimento irrepetivel no tempo e no espaço. Esse princípio arquitetônico possui três momentos fundamentais: eu-para-mim (imagem que o eu, desdobrado em outro interno, possui de si); o outro-para-mim (imagem que o eu tem do outro externo, seja ele mesmo - um outro de si - ou um outro seu - diferente e apartado de si. Dado esse desdobramento, o eu passa a ser uma espécie de outro-do-outro que, por sua vez, torna-se um eu) e o eu-para-o-outro (imagem que o outro externo - diferente de si - tem do eu). De acordo com o filósofo russo, "todos os valores da cultura se dispõem ao redor destes pontos arquitetônicos fundamentais do mundo real do ato: valores científicos, estéticos, políticos (incluidos também os éticos e sociais) e finalmente, religiosos" (BAKHTIN, 2010, p. 114).

A consciência, desse modo, deixa ser o ponto de partida do mundo concreto, para ser a consciência concreta da participação do eu na existência, encarada como evento singular, constituida socialmente na relação dialógica com o(s) outro(s), uma vez que "ser realmente vida significa agir" (BAKHTIN, 2010, p. 99) por meio de atos de linguagem. Esse mundo, continua Bakhtin, em que o ato realmente acontece, "é um mundo unitário e singular concretamente vivido: é um mundo visivel, audivel, tangivel, pensável, inteiramente permeado pelos tons emotivo-volitivos da validade de valores assumidos como tais" (2010, p. 117).

A participação dos sujeitos no mundo-existir único também ocorre de forma singular, pois cada individuo ocupa um lugar igualmente único em relação ao outro. Na exata posição temporal-espacial em que um sujeito se encontra em determinado momento da história, nenhum outro nunca esteve, nem ninguém estará. Todo e qualquer ato realizado por determinado sujeito não poderá jamais ser efetuado da mesma maneira e com a mesma significação por outro alguém. Uma mesma palavra proferida, um mesmo movimento corporal feito, uma mesma nota musical tocada com o mesmo instrumento, seja por outro ou pelo mesmo sujeito, todos esses atos serão distintos, singulares no Ser-evento do mundo-existir. Essa singularidade é irrevogável. A corporeidade da palavra é única, tanto quanto o sujeito, em ato, na existência prática (pravda), o é.

O sujeito é insubstituível, essa condição singular foi lhe dada, mas, simultaneamente, a singularidade só existe, bem como do próprio sujeito, a partir do momento em que o sujeito faz uso dela - coloca-a em prática por meio de seus atos (sempre, de linguagem). Em outras palavras, o sujeito e sua singularidade só podem e devem se realizar na participação do mundo-existir por meio do ato enunciativo. Ainda que seja um ato enunciativo interior (um pensamento) ou mesmo um aparente não-agir, o sujeito age e o faz do seu lugar singular.

O reconhecimento dessa singularidade assume o ato em seu sentido duplo: responsável, porquanto a realização do ato é feita por um sujeito único e insubstituivel no mundo-existir, o que confere ao próprio ato irrepetibilidade; e responsivo, pois possui uma orientação social, direcionado a um outro (ainda que seja um outro interno, eu-para-mim), ao qual responde (memória de passado) e gera novas respostas (memória de futuro) e outros atos, realizados por sujeitos singulares no elo da cadeia discursiva. Afinal, tudo no sujeito, "cada movimento, cada gesto, cada experiência vivida, cada pensamento, cada sentimento - deve ser um ato responsável; é somente sob esta condição que eu realmente vivo [...]" (BAKHTIN, 2010, p. 101). Nesse sentido, segundo Geraldi (2010, p. 287), quando agimos,

\begin{abstract}
somos responsáveis pela compreensão construida que passa a ser o sentido do evento. Somos responsáveis por isso, e duplamente responsáveis porque as ações que nosso ato desencadear no futuro (ações de outros ou minhas) resultarão, por seu turno, de uma compreensão que não remete mais somente ao meu ato, mas também ao ato de que meu ato foi resposta. Em outros termos, a responsabilidade "responsiva" tem dupla direção, tanto para o passado quanto para o futuro, ainda que concretamente seja sempre realizada no presente.
\end{abstract}

Fora do enunciado, o homem, tampouco o mundo, existe. A vida é dialógica por excelência. A única forma adequada para a expressão do in- 
dividuo é no diálogo inconcluso. Ser é agir e agir significa participar do diálogo. Para isso, o homem "participa inteiramente e com toda sua vida: com os olhos, os lábios, as mãos, a alma, o espírito, todo o corpo, os atos" (BAKHTIN, 2011, p. 348). O homem se põe todo na linguagem, que penetra no tecido dialógico da própria vida humana.

Desse modo, ao realizar-se e realizar (n)o ato enunciativo, o sujeito toma forma, existência, assume para si, por meio do outro, uma concretude, integridade, responsividade, inesgotabilidade, inconclusibilidade, Características presentes também no enunciado ou, como temos chamado até o momento, no ato enunciativo. Assim, ao falarmos de enunciado, pressupomos a linguagem, que, por sua vez, remete-nos ao próprio homem.

Para o Círculo, todos os campos de atividade humana estão associados ao uso da linguagem, empregada por meio de enunciados únicos e concretos. Eles, os enunciados, possuem relação imediata com o mundo (o real inapreensivel diretamente), refletem e refratam as condições materiais, bem como a finalidade de cada campo de criação ideológica do homem. Esses aspectos aparecem no todo do conjunto enunciativo, ou seja, nos seus elementos constitutivos, a saber, conteúdo temático, forma e estilo.

Em outras palavras, a linguagem passa a integrar a vida por meio de enunciados porque eles a concretizam e, ao mesmo tempo, pelos enunciados, a vida entra na linguagem, torna-a viva, dinâmica, em movimento, plena de relações dialógicas, como é a própria história do homem. A história da sociedade e a história da linguagem se refletem mutuamente nos enunciados. Para entender a organização social do homem, olhamos a sua linguagem (suas criações e registros); e, para compreender a linguagem, observamos a vida social humana na qual está inserida, uma vez que os enunciados são situados sócio-histórico-culturalmente. Linguagem e homem são indissociáveis porque o humano conhecido é aquele expresso e a linguagem, como concepção humana, cognitiva, é semiótica.

Pela sua função semiótica e sociocultural, o enunciado é composto por elementos de lin- guagem e sócio-históricos. Ao que concerne à linguagem, além dos componentes explícitos, o enunciado é composto, também, por questões presumidas, não expressas, mas existentes de forma subentendida, que ultrapassa os limites do material, sem a qual é impossivel compreender o enunciado, uma vez que, apartado dela, perde sua significação.

Em outras palavras, além dos elementos da linguagem, o enunciado é materializado em um tempo (quando) e em um espaço (onde), refere-se a determinado objeto (sobre o que) e se relaciona com um interlocutor (quem - um outro) sobre o objeto. Com isso, um mesmo elemento de linguagem (a palavra "bem", uma cor, um som etc.) pode ter sentidos diferentes, de acordo com a situação enunciativa na qual se realiza. Cada contexto social envolve a comunicação discursiva e contribui para organizar, construir e finalizar o enunciado, em determinada esfera de atividade humana. A situação é a realização efetiva das formas de comunicação discursiva. Para sua realização, o enunciado parte das condições materiais de produção da sociedade, para a comunicação social até chegar à interação discursiva real. Conforme expõe Volóchinov, em "Discurso na vida, discurso na arte" ,

O significado e a importância de um enunciado
na vida (seja qual for a espécie particular deste
enunciado) não coincidem com a composição
puramente verbal do enunciado. Palavras ar-
ticuladas estão impregnadas de qualidades
presumidas e não enunciadas. O que se chama
de "compreensão" e "avaliação" de um enun-
ciado (concordância ou discordância) sempre
engloba a situação pragmática extraverbal
juntamente com o próprio discurso verbal. A
vida, portanto, não afeta um enunciado de fora;
ela penetra e exerce influência num enunciado
de dentro, enquanto unidade e comunhão da
existência que circunda os falantes e unidade
e comunhão de julgamentos de valor essen-
cialmente sociais, nascendo deste todo sem o
qual nenhum enunciado inteligivel é possivel.
A enunciação está na fronteira entre a vida e
o aspecto verbal do enunciado; ela, por assim
dizer, bombeia energia de uma situação da
vida para o discurso verbal, ela dá a qualquer
coisa lingüisticamente estável o seu momento
histórico vivo, o seu caráter único ([1926?], p. 10).

A constatação de o enunciado ser sempre situado marca, por conseguinte, seu caráter dia- 
lógico, pois, sendo o enunciado um conjunto de sentido na unidade real da comunicação discursiva, torna-se dialógico por natureza. Ele não pode ser concebido isoladamente, pois pressupõe enunciados anteriores e sucessores, de maneira a nunca ser o primeiro nem o último, mas um elo na corrente discursiva. Enquanto unidade real da comunicação discursiva, o enunciado tem os seus limites definidos a partir de três peculiaridades: alternância entre os sujeitos; conclusibilidade; e sua relação com os sujeitos (BAKHTIN, 2016).

A alternância entre os sujeitos marca precisamente o início e o fim de um determinado enunciado. Antes do começo do enunciado, há enunciados anteriores a ele, aos quais responde; depois do seu término, outros enunciados responsivos, os quais the responderão. Essa interação abre a possibilidade para a responsividade, pois o sujeito conclui seu enunciado em posição ao outro, como réplica discursiva inacabada e contínua.

Os atos enunciativos responsivos podem e são os mais diversos possiveis e estão condicionados às funções que a linguagem ocupa nas condições de comunicação dentro de cada campo de atividade humana. A expressividade de tais atos pode ocorrer de forma verbal, visual, sonora e/ou sincrética. Uma ordem militar pode ter resposta com uma ação/gesto (bater continência); um comportamento inadequado de uma criança pode ter como réplica uma reação verbal dos pais (ao repreendê-la); o choro de um amigo, ser respondido com um abraço ou mesmo uma compreensão (ativa) silenciosa; e assim por diante.

A conclusibilidade (sempre provisória) do enunciado é constituida por três aspectos: a exauribilidade do tema, em que o sujeito escolhe o quanto deseja ou não externalizar sobre dado objeto; o projeto discursivo do sujeito, como ele define a arquitetônica da construção enunciativa (o que expressa, o quanto expressa e como expressa); e, por fim, a opção por determinado gênero discursivo. A conclusibilidade revela o caráter individual de cada enunciado (que pode ser observado com mais clareza pelo elemento estilístico), que o faz ser diferente dos demais, único e irrepetivel. Mas, essa individualidade está submetida às condições possiveis (potenciais) da configuração da comunicação discursiva.

A construção do enunciado leva em consideração a sua relação com o autor-criador e com os integrantes da comunidade discursiva. A escolha do gênero e dos elementos de linguagem (a cor usada, a tonalidade, a construção frasal, o léxico, o movimento de câmera, do corpo, o ângulo da fotografia, o acorde etc.) é determinada pelo objetivo (o projeto de dizer) do sujeito em relação com o objeto sobre o qual se expressa e com o sentido a ser lhe atribuido. Outro elemento que determina as peculiaridades estilístico-composicionais é a relação subjetiva emocionalmente valorativa do sujeito para com o objeto, em sua dupla orientação: "uma em relação ao interlocutor como aliado ou testemunha, e outra em relação ao objeto do enunciado como um terceiro participante vivo" (VOLOSHINOV, [1926?], p. 9). O sujeito se apoia nessas duas bases para a construção enunciativa.

Essas são as peculiaridades do enunciado que definem seu traço fundamental constitutivo: a orientação social. A construção do ato enunciativo (a alternância de sujeitos, a conclusibilidade e a sua construção) está voltada para o outro, tanto a outros discursos anteriores quanto a outros enunciados futuros, aos quais o sujeito antecipa as respostas (embora possa não coincidir, como muitas vezes ocorre). Ela é "indissociável do convívio dialógico, por sua própria natureza quer ser ouvida e respondida" (BAKHTIN, 2011, p. 356). O enunciado se relaciona com o próprio sujeito e com os outros sujeitos da comunidade discursiva, é endereçado ao outro (enunciado e sujeito)

O endereçamento do enunciado pode ter como destinatário as mais diversas possibilidades: alguém próximo na réplica do cotidiano, um povo, um grupo social, um auditório específico, um chefe, o próprio sujeito (em forma de monólogo, o eu torna-se outro para si mesmo, por isso, ele é também é considerado dialógico) ou até mesmo um endereçado imaginado, desde que tenha um interlocutor para polemizar, concordar, discordar, parodiar, enfim, responder-lhe, por uma compreensão ativa que seja. Por mais 
monológico que seja um enunciado - uma obra cientifica ou divagações interiores, por exemplo -, ele está orientado para o social e se volta responsivamente a outros enunciados. O destinatário não precisa pertencer ao mesmo campo de atividade humana, pois é possivel o contato entre enunciados de diferentes esferas e cronotopos, convergentes no tema, na forma ou no estilo, ainda que em tons emotivo-voltivos e valorativos distintos (de maneira semelhante ou opositiva).

Essa orientação social para outro implica, inevitavelmente, em considerar as relações dialógicas a partir da hierarquia social, a qual estabelece a construção do enunciado em função de quem se expressa, para quem se expressa, sobre o que se expressa, como o faz, quando e onde se expressa. Essa condição influencia todos os aspectos dos enunciados aqui tratados e não se restringe ao discurso verbal, mas a todo e qual enunciado do homem, desde o momento do seu nascimento, em que ele é colocado todo na linguagem. Segundo Volóchinov (2019), a forma exterior corporal do comportamento social do homem - movimento das mãos, pose, expressão facial, tom de voz - integra o enunciado e "é determinada principalmente pela consideração e, por conseguinte, pela avaliação corresponde do auditório presente" (2019, p. 281). Em outras palavras, a orientação social marca o caráter dialógico do enunciado.

As relações dialógicas, para Bakhtin, "devem personificar-se na linguagem, tornar-se enunciados, converter-se em posições de diferentes sujeitos expressas na linguagem para que entre eles possam surgir relações dialógicas" (2015a, p. 209). Isso ocorre porque as relações dialógicas são relações de sentido, ou seja, relações entre enunciados - lembremo-nos que assim Bakhtin (2011) define enunciado como um "conjunto de sentido". Toda relação com o e de sentido é dialógica por excelência. Como todo enunciado possui sentido, todo enunciado é dialógico como citamos, baseados em Volóchinov (2017), até mesmo o monólogo interior).

Na própria compreensão de uma unidade de sentido - enunciado - revela-se uma especifi- cidade dialógica, pois a relação com o sentido é dialógica, já que é impossivel se relacionar com ele sem antes passar a participar do diálogo. Essa é a especificidade das Ciências Humanas, em que se faz necessário entrar no contexto dialógico para que se possa compreender o objeto (enunciado e homem) e seus sentidos processuais.

A compreensão possui caráter dialógico, pois seu ato envolve a responsividade e a avaliação (juizo de valor) do enunciado do outro. Toda compreensão está impregnada de resposta, uma vez que ela é uma preparação para responder ao outro. E, para replicar, aquele que o faz exige uma avaliação, a partir da sua concepção de mundo e do seu posicionamento axiológico único na existência, do que é expresso verbal, visual e/ ou sonoramente.

Essa compreensão ativamente responsiva, de acordo com Bakhtin (2016), não precisa aparecer como outra fala (discurso verbal, por exemplo) ou ter uma resposta imediata. Ela pode, como apontamos com alguns exemplos, realizar em uma ação prática - um gesto, uma expressão facial, o cumprimento de uma ordem - ou mesmo em pleno silêncio. Todas essas formas (e outras tantas) constituem-se como enunciados. Volóchinov (2013), ao refletir sobre a questão em "A construção da enunciação", complementa: "habitualmente, respondemos a todo enunciado, se não com palavras, ao menos com gestos: o movimento das mãos, o sorriso, o balanço da cabeça etc" (2013, p. 272). Essa responsividade é frequente, por exemplo, em discursos de tendência mais monológica, como é o caso de uma palestra ou um discurso oficial em rede nacional. Ainda segundo Volóchinov, nessas situações, "cada movimento de um ou de outro ouvinte sua pose, sua expressão facial, o leve tossir, a mudança de posição -, tudo isso [...] serve de resposta clara e expressiva" (2013, p. 272).

No discurso interior, as relações dialógicas estão igualmente presentes, ainda que talvez o interlocutor não seja evidente em um primeiro momento. Nossos pensamentos se desmembram em réplicas (perguntas, respostas, afirmações 
e negações), como se tivéssemos duas vozes (valorações sociais) em nossa consciência, uma que se funde ao nosso ponto de vista e outra que se torna representante de nossa classe, da pessoa com a qual imaginamos falar (escrever, pintar, compor), do nosso auditório etc. Às vezes, esse processo se complexifica ainda mais se pensarmos na presença, totalmente possivel, de mais vozes, como é caso de valores religiosos, entre outros do ambiente sociocultural.

A depender de cada situação, nós reproduzimos em nossa mente, como ideia, a imagem do outro, representante de dado posicionamento social, a entonação, as possiveis reações dele, os gestos, as expressões corporais e faciais, criamos o cenário mais completo que pudermos no qual o drama (como no ambiente romanesco) se desenvolve. Tudo isso em nossa consciência. Quanto mais conhecemos nosso interlocutor e a situação sócio-histórica ambiente, mais real se torna a cena. Os exemplos que comprovam isso são os mais variados: uma entrevista de emprego, o encontro com a pessoa amada, a preparação de uma surpresa, a construção de uma obra de arte, um artigo científico, a estreia de uma peça teatral, o planejamento de aula, um pronunciamento oficial, dentre inúmeros outros.

Partindo dessa lógica dos autores do Círculo, percebemos que, na comunicação discursiva, seja no cotidiano seja no grande tempo da cultura, articulamos as potencialidades de construção de sentido (de resposta) oferecidas pela linguagem (verbal, sonora e visual), quais se materializam no enunciado de acordo com o gênero no qual a comunicação está inserida, mas, em todos os casos, essas potencialidades existem na compreensão ativa no interior da consciência, constituida por material sígnico (VOLÓCHINOV, 2017, 2019). Ademais, a reação não se dá unilateralmente (do verbal para o visual ou o vocal/sonoro). As formas de interação são tantas quanto os modos de condição de atividade humana.

Nesse sentido, a relação dialógica se dá de forma verbivocovisual a partir das marcas e dos vestígios deixados pelo sujeito em seu enunciado, pois, ao se expressar, ele utiliza as formas que the forem possiveis - seja no traço do pincel, no gesto, na expressão facial, na entonação, na cadência de uma música, numa obra literária etc - , condicionadas às delimitações impostas pelo gênero, como assumido pelo Círculo, conforme citamos no trecho de Volóchinov e no excerto seguinte, agora, de Bakhtin, no qual o filósofo russo expõe que

Toda compreensão é, em maior ou menor grau, prenhe de reação responsiva quer em palavras, quer em ação. [...] no grau e no caráter do ativismo da compreensão existe uma diferença essencial entre o monólogo e o diálogo. Esse ativismo especial da intercompreensão dialógica determina a ação, o dramatismo do discurso dialógico (2016, p. 122).

Podemos reagir, por exemplo, a um concerto (materialmente sonoro) por meio de um sorriso ou pelo escorrer de uma lágrima (resposta visual), acompanhado de exclamações, como "Bravo!". Isso significa que, independente de se concretizar em nossa fala ou não, já está latente na exteriozação da nossa expressão corporal. Do ponto de vista do processo de reflexo e refração da realidade, não teria o mesmo sentido, posto a singularidade do discurso. Aqui não nos referimos à equivalência entre as linguagens, mas a suas interrelações constitutivas, em como as linguagens aparecem potencialmente concretizadas umas nas outras, principalmente ao considerarmos o processo dialógico da compreensão ativa.

\section{Considerações finais (não acabadas)}

A reflexão feita a partir das noções de linguagem e enunciado para o Círculo bakhtiniano nos permite pensar sobre a relevância dessa perspectiva filosófica para os estudos da linguagem de maneira atemporal e genérica, dada a atualidade das ideias propostas pelos autores e a preocupação com as mais variadas manifestações de linguagem ${ }^{7}$ que orbitam seu escopo de estudo; e sobre como as linguagens verbal, visual e sonora, 
divididas cartesianamente na tradição ocidental, articulam-se, combinam-se e, diríamos mesmo, constituem uma única linguagem para o homem exprimir-se em forma de enunciados genéricos, os quais se concretizam em relações dialógicas por meio de materialidades verbivocovisuais, uma vez que "em tudo através do que o homem se exprime exteriormente (e, por conseguinte, para o outro) - do corpo à palavra - ocorre uma tensa interação do eu com o outro" (BAKHTIN, 2011, p. 350, grifo do autor).

A formulação da filosofia da linguagem bakhtiniana possui uma concepção de linguagem única, uma linguagem das linguagens, por assim dizer, que se caracteriza pela potencialidade das diversas linguagens que, por sua vez, materializam-se com suas lógicas sistêmicas especificas e podem ou não se relacionar de maneira explícita, a depender do projeto de dizer autoral arquitetônico do autor-criador e do gênero discursivo catalizador do enunciado. Essa noção é mobilizada pelos membros do Círculo, principalmente em seu periodo maduro em Leningrado (1924-1929), para refletir sobre as questões pertinentes ao contexto soviético. Contudo, diante da atmosfera hostil a partir dos anos 1930, com a subida de Stalin ao cargo, a formulação desse conceito foi interrompida e desenvolvida por Bakhtin posteriormente, sobretudo em o "Problema do texto na linguística, na filologia e nas ciências humanas", no qual afirma que

Todo sistema de signos (isto é, qualquer língua), por mais que sua convenção se apoie em uma coletividade estreita, em principio sempre pode ser codificada, isto é, traduzido para outros sistemas de signos (outras linguagens); consequentemente, existe uma lógica geral dos sistemas de signos, uma potencial linguagem das linguagens única (que, evidentemente, nunca pode vir a ser uma linguagem única concreta, uma das linguagens) (BAKHTIN, 2011, p. 311).

Com base nessa perspectiva é que Paula
(2017), Paula e Serni (2017) e Paula e Luciano (2020a, 2020b, 2020c, 2020d, 2020e) denominam essa "linguagem das linguagens única" como verbivocovisual, dada a sua constituição tridimensional, seja ao pensarem a sua potencialidade semiótica (imagem mental e acústica), seja explicitada em enunciados específicos (visuais, vocais/ sonoros, verbais ou sincréticos - multimodais).

De acordo com Paula e Luciano (2020e), a verbivocovisualidade se refere a uma concepção de linguagem formulada por Joyce e desenvolvida pela Poesia Concreta (1975). A poesia concreta utiliza essa noção em sua potencialidade máxima de interrelação indissociável, em que a materialidade compreende a linguagem como um objeto tridimensional, uma célula viva, que traduz o mundo e o homem em palavra-coisa.

Em vista disso, assumimos como adequada a apropriação do termo para pensar a concepção de linguagem proposta pelo Círculo, posto que os intelectuais russos concebem, como dissemos, a linguagem não como mera representação do homem e do mundo de maneira mimética, mas como lugar de existência, ou seja, "mundo dos signos", onde habita o sujeito (de linguagem). Nesse sentido, o corpo do homem, de certa forma, é o corpo da linguagem. Linguagem material, enunciada em todas as suas formas, como afirma Bakhtin:

O corpo exterior do homem é dado, suas fronteiras exteriores e seu mundo são dados (na concretude extraestética da vida), são um elemento indispensável e insuperável da concretude da existência, daí que necessitam, consequentemente, da recepção estética, de recriação, elaboração e justificação, é o que se faz por todos os meios de que a arte dispõe: cores, linhas, volumes, palavras, sons. Visto que o artista lida com a existência e o mundo do homem, lida também com a sua concretude espacial, com suas fronteiras exteriores como elemento indispensável dessa existência, e, ao transferir essa existência do homem para o plano estético, deve transferir para esse plano também a imagem externa dela nos limites

\footnotetext{
Ao contrário. Muitas vezes, a partir do romance e como justificativa para a eleição desse gênero como foco de seus estudos, Bakhtin Volóchinov e Medviédev, entre outros componentes do Circulo, argumentam que o romance semiotiza a vida e, por vezes, incorpora, nele, outras manifestações e gêneros discursivos. Assim, a leitura em voz alta, a entonação, a expressão corporal e facial, os gestos, entre outros elementos, são considerados em seus estudos. Além disso, diferente da ideia non sense de que o Círculo não se preocupou com outros gêneros e linguagens, há produções que contradizem essa afirmação: Volóchinov estudou e escreveu sobre música de concerto: Sollertinskij (2016), ópera; Jakubinskij (2015), oralidade; Medviédev, teatro; Bakhtin, mesmo ao se voltar ao romance, toca em questões voltadas ao teatro e à poesia. Esses exemplos demonstram a variedade do pensamento do "coletivo pensante" (MEDVIÉDEV; MEDVIEDEVA, 2014) bakhtiniano e sua preocupação com a linguagem e suas manifestações diversas.
} 
determinado pela espécie do material (cores, sons etc.)" (BAKHTIN, 2011, p. 86-87).

O Círculo reflete sobre a atividade estética, sempre ética, constitutiva e constituinte das dimensões da vida e da cultura (BRANDIST, 2002), mas não só, pois também se volta a variações linguísticas, oralidade, enunciados cotidianos, entre outros. Não é o objetivo deste artigo refletirmos sobre isso, por isso, não desenvolveremos aqui essa questão ou mesmo noções metodológicas específicas de análise. Citamos apenas para termos da amplitude do espectro bakhtiniano, sua riqueza e relevância. Interessou-nos, aqui, abordarmos as noções de linguagem e enunciado, consideradas como concepções potenciais e materiais que incorporam o homem e o mundo, pois lugares de existência. Sem a expressão linguageira, o humano se desumaniza, sequer existe. Sem corpo, a alma não se expressa e apenas a abstração ideal e irreal paira no ar. Mas, não se expressa de qualquer maneira. Há regras sistêmicas e socioculturais, ou então, cairiamos num outro extremo, o subjetivismo sem limites. As singularidades enunciativas respeitam as possibilidades potenciais do corpo da linguagem. Enunciado e linguagem, a nosso ver, com base nos estudos bakhtinianos, como vimos, potencial ou explicitamente, verbivocovisuais.

\section{Referências}

BAKHTIN, M. Estética da Criação Verbal. Tradução de Paulo Bezerra. 6. ed. São Paulo: Martins Fontes, 2011.

BAKHTIN, M. Os gêneros do discurso. São Paulo: Editora 34, 2016.

BAKHTIN, M. Para uma filosofia do ato responsável. São Carlos: Pedro e João Editores, 2010.

BAKHTIN, M. Problemas da Poética de Dostoiésvki. Rio de Janeiro: Forense Universitária, 2015a.

BAKHTIN, M. Teoria do Romance I - A Estilistica. São Paulo: 34, 2015b.

BAKHTIN, M. A cultura popular na ldade Média e no Renascimento: o contexto de François Rabelais. São Paulo: Hucitec, 1987.
BAKHTIN, M. (VOLOSHINOV, V.). Discurso na Vida, Discurso na Arte (Sobre a Poética Sociológica). Tradução de Carlos Alberto Faraco e Cristóvão Tezza para fins acadêmicos [Mimeo], a partir da tradução inglesa de I. R. Titunik ("Discourse in life and discourse in art concerning sociological poetics"), publicada em V. N. Voloshinov, [1926?].

Freudism, New York: Academic Press, 1976.

BRANDIST, C. The Bakhtin Circle: Philosophy, Culture and Politics. London: Pluto Press, 2002.

CAMPOS, A. de; PIGNATARI, D. CAMPOS, H. de. Teoria da Poesia Concreta. São Paulo: Livraria Duas Cidades, 1975.

GERALDI, J. W. Sobre a questão do sujeito. In: PAULA, L. de; STAFUZZA, G. B. (org.). Circulo de Bakhtin - teoria inclassificável. Campinas: Mercado de Letras, 2010. p. 279-292. (Série Bakhtin Inclassificável, v. 1).

JAKUBINSKIJ L. Sobre a fala dialogal. São Paulo: Parábola, 2015.

MEDVIÉDEV, P. O Método Formal nos estudos literários. São Paulo: Contexto, 2012.

MEDVIÉDEV, I. P.; MEDVIÉDEVA, D. A. O Círculo de M. M. Bakhtin: sobre a fundamentação de um fenômeno. Bakhtiniana, [S. l.], v. 9. p. 26-46, jun. 2014. Disponivel em: https://revistas.pucsp.br/bakhtiniana/article/ view/11535. Acesso em: 20 maio 2020.

PAULA, L. de. O enunciado verbivocovisual de animação - a valoração do "amor verdadeiro" Disney - uma análise de Frozen. In: FERNANDES JR., A.; STAFUZZA, G. B. (org.). Discursividades Contemporâneas - política, corpo e diálogo. Campinas: Mercado de Letras, 2017. p. 287-314. (Série Estudos da Linguagem).

PAULA, L. de; LUCIANO, J. A. R. A filosofia da linguagem bakhtiniana e sua tridimensionalidade verbivocovisual. Revista Estudos Linguísticos, São Paulo, v. 49, n. 2, p. 706-722, 2020a. Disponivel em: https://revistas.gel. org.br/estudos-linguisticos/article/view/2691. Acesso em: 4 jul. 2020.

PAULA, L. de; LUCIANO, J. A. R. A tridimensionalidade verbivocovisual da linguagem bakhtiniana. Linha D'Água, São Paulo, v. 33, n. 3, p. 105-134, 2020b. Disponivel em: https://www.revistas.usp.br/linhadagua/ article/view/171296. Acesso em: 17 dez. 2020.

PAULA, L. de; LUCIANO, J. A. R. Dialogismo verbivocovisual uma proposta bakhtiniana. Polifonia, Cuiabá, v. 27, n. 49, p. 15-46, 2020c. Disponivel em: https:// periodicoscientificos.ufmt.br/ojs/index.php/polifonia/ article/view/11366. Acesso em: 13 abr. 2021.

PAULA, L. de; LUCIANO, J. A. R. Filosofia da linguagem bakhtiniana: concepção verbivocovisual. Revista Diálogos - RevDia, Cuiabá (MT), v. 8, n. 3, p. 132-151, 2020d. Disponivel em: https://periodicoscientificos.ufmt.br/ ojs/index.php/revdia/article/view/10039. Acesso em: 30 out. 2020

PAULA, L. de; LUCIANO, J. A. R. Recepções do pensamento bakhtiniano no Ocidente: a verbivocovisualidade no Brasil. In: BUTURI Jr, A.; BRAGA, S.; SOARES, T. B. No campo discursivo: teoria e análise. Campinas: Pontes, 2020e. 
PAULA, L.; SERNI, N. M. A vida na arte: a verbivocovisualidade do gênero filme musical. Raido, Dourados, v. 11, n. 25, p. 178-201, jul. 2017. Disponivel em: https:// ojs.ufgd.edu.br/index.php/Raido/article/view/6507. Acesso em: 10 out. 2020

PONZIO, A. No Círculo com Mikhail Bakhtin. São Carlos: Pedro \& João, 2016

SOLLERTINSKIJ, I. I. Musica e letteratura al tempo dell'Unione Sovietica. Italia: Lucca: I Quaderni di M/R: LIM Editrice, 2016

VOLÓCHINOV, V. A palavra na vida e a palavra na poesia. São Paulo: 34, 2019

VOLÓCHINOV, V. Marxismo e Filosofia da Linguagem. São Paulo: 34, 2017

VOLÓCHINOV, V. A construção da enunciação e outros ensaios. São Carlos: Pedro \& João, 2013.

\section{Luciane de Paula}

Professora do Departamento de Estudos Linguísticos, Literários e da Educação da Universidade Estadual Paulista (UNESP), em Assis, SP, Brasil; e do Programa de Pós-Graduação em Linguistica e Lingua Portuguesa da UNESP, em Araraquara, SP, Brasil.

\section{José Antonio Rodrigues Luciano}

Doutorando pelo Programa de Pós-Graduação em Linguística e Lingua Portuguesa da Universidade Estadual Paulista (UNESP), em Araraquara, SP. Brasil.

\section{Endereço para correspondência:}

\section{Luciane de Paula}

Universidade Estadual Paulista

Av. Dom Antônio, 2100

Parque Universitário, 19806-900

Assis, SP, Brasil

José Antonio Rodrigues Luciano

Rod. Araraquara-Jaú Km 1

Machados, 14800-901

Araraquara, SP, Brasil

Os textos deste artigo foram revisados pela Poá Comunicação e submetidos para validação do(s) autor(es) antes da publicação. 